\title{
Apportioning of Risks via Stochastic Dominance
}

\author{
LOUIS EECKHOUDT \\ HARRIS SCHLESINGER \\ ILIA TSETLIN
}

\author{
CESIFO WORKING PAPER NO. 2467 \\ CATEGORY 10: EMPIRICAL AND THEORETICAL METHODS
}

NOVEMBER 2008

\footnotetext{
An electronic version of the paper may be downloaded

- from the SSRN website: Www.SSRN.com

- from the RePEc website: $\quad$ www.RePEc.org

- from the CESifo website: www.CESifo-group.org/wp
} 


\title{
Apportioning of Risks via Stochastic Dominance
}

\begin{abstract}
Consider a simple two-state risk with equal probabilities for the two states. In particular, assume that the random wealth variable $X_{i}$ dominates $Y_{i}$ via $i^{\text {th }}$-order stochastic dominance for $\mathrm{i}=\mathrm{M}, \mathrm{N}$. We show that the 50-50 lottery $\left[\mathrm{X}_{\mathrm{N}}+\mathrm{Y}_{\mathrm{M}}, \mathrm{Y}_{\mathrm{N}}+\mathrm{X}_{\mathrm{M}}\right]$ dominates the lottery $\left[\mathrm{X}_{\mathrm{N}}+\right.$ $\left.\mathrm{X}_{\mathrm{M}}, \mathrm{Y}_{\mathrm{N}}+\mathrm{Y}_{\mathrm{M}}\right]$ via $(\mathrm{N}+\mathrm{M})^{\text {th }}$-order stochastic dominance. The basic idea is that a decision maker exhibiting $(\mathrm{N}+\mathrm{M})^{\text {th }}$-order stochastic dominance preference will allocate the statecontingent lotteries in such a way as not to group the two "bad" lotteries in the same state, where "bad" is defined via $\mathrm{i}^{\text {th }}$-order stochastic dominance. In this way, we can extend and generalize existing results about risk attitudes. This lottery preference includes behavior exhibiting higher order risk effects, such as precautionary effects and tempering effects.
\end{abstract}

JEL Code: D81.

Keywords: downside risk, precautionary effects, prudence, risk apportionment, risk aversion, stochastic dominance, temperance.

Louis Eeckhoudt
Catholic University of Mons
CORE
34 Voie du Roman Pays
1348 Louvain-la-Neuve
Belgium
eeckhoudt@fucam.ac.be

Ilia Tsetlin

INSEAD

1 Ayer Rajah Ave

138676 Singapore

\author{
Harris Schlesinger \\ Department of Finance \\ University of Alabama \\ 200 Alston Hall \\ Tuscaloosa, AL 35487-0224 \\ USA \\ hschlesi@cba.ua.edu
}

November 6, 2008

The authors thank two anonymous referees, as well as Paul Kleindorfer, Claudio Mezzetti, Kirsten Rohde, Tim Van Zandt, and seminar participants at the University of Paris Dauphine, Paris School of Economics, University of Verona, Université Louis Pasteur (Strasbourg) and the 2007 EGRIE meeting for helpful comments. Ilia Tsetlin's research was supported in part by the Center for Decision Making and Risk Analysis at INSEAD. 


\section{Introduction}

Choice under uncertainty is often model specific. Much debate in the literature discusses the pros and cons of the various types of valuation methods used in modeling such decisions. The choice is made much easier when we have stochastic dominance by one of the alternatives. In such a case, we will have agreement on the optimal choice by a wide range of valuation methods. For example, suppose a corporation believes its shareholders are all risk averse, defined as an aversion to mean-preserving spreads. ${ }^{1}$ Its shareholders would then unanimously favor a decision yielding the random payout variable $\widetilde{X}$ over the alternative set of payoffs $\widetilde{Y}$, whenever $\widetilde{X}$ dominates $\widetilde{Y}$ via second-order stochastic dominance (SSD). This holds true for any model of preferences that preserves a preference for SSD. For example, in an expected-utility framework, this would hold whenever the utility function is increasing and concave. The link between stochastic dominance and preferences within an expected-utility

\footnotetext{
${ }^{1}$ See Rothschild and Stiglitz [25].
} 
framework is particularly well known. If we restrict the utility function $u$ to be differentiable, then $N^{t h}$-order stochastic dominance (NSD) of $\widetilde{X}$ over $\widetilde{Y}$ is equivalent to unanimous preference of $\widetilde{X}$ over $\widetilde{Y}$ by any individual whose utility exhibits certain properties. This equivalence has implications for non-expected utility models as well. For example, suppose that all individuals satisfying NSD preference unanimously prefer $\widetilde{X}$ to $\widetilde{Y}$ within an expected-utility framework. Then any non-expected utility preference functional that satisfies NSD preference would also lead to the choice of $\widetilde{X}$ over $\widetilde{Y}^{2}$

Consider the independent random variables $\widetilde{X}_{N}, \widetilde{Y}_{N}, \widetilde{X}_{M}$ and $\widetilde{Y}_{M}$, and assume that $\widetilde{X}_{i}$ dominates $\widetilde{Y}_{i}$ via $i^{\text {th }}$-order stochastic dominance for $i=M, N$. We show that the $50-50$ lottery $\left[\widetilde{X}_{N}+\widetilde{Y}_{M}, \widetilde{Y}_{N}+\widetilde{X}_{M}\right]$ dominates the lottery $\left[\widetilde{X}_{N}+\widetilde{X}_{M}, \widetilde{Y}_{N}+\widetilde{Y}_{M}\right]$ via $(N+M)^{t h}$-order stochastic dominance. We also show that this result holds true if we replace stochastic dominance with the special case of an $i^{t h}$-degree increase in risk, as defined by Ekern [8].

These rankings have implications for choice problems within particular classes of valuation functionals over distribution functions. For the case of $i^{t h}$-degree increases in risk, this characterization is shown to generalize the concept of risk apportionment, as introduced by Eeckhoudt and Schlesinger [5]. For both $i^{\text {th }}$-degree increases in

\footnotetext{
${ }^{2}$ A similar point was made by Zilcha and Chew [29].
} 
risk and stochastic dominance, we show how such lottery preference induces behavior exhibiting higher-order risk effects, such as precautionary effects and tempering effects. We use this interpretation to show how risk-management behavior typically involves more than just the hedging of risks. Indeed, hedging occurs as a special case where $M=N=1$, where relatively good outcomes for one asset are paired with relatively bad outcomes for another asset, and vice versa.

The next two sections present our basic model and main results. We then provide several applications of our results to decsion making under risk and conclude by discussing the implications of higher-order risk effects for risk-management behavior.

\section{Stochastic Dominance and $N^{t h}$ Degree Risk}

We start with a definition of stochastic dominance. ${ }^{3}$ Assume that all random variables have bounded supports contained within the interval $[a, b]$. Let $F$ denote the cumulative distribution function for such a random variable. Define $F^{(0)}(x) \equiv F(x)$ and define $F^{(i)}(x) \equiv \int_{a}^{x} F^{(i-1)}(t) d t$ for $i \geq 1$.

Definition 1 The distribution $F$ weakly dominates the distribution $G$ in the sense of $N^{\text {th }}$-order stochastic dominance if

\footnotetext{
${ }^{3}$ See, for example, Ingersoll [13] and Jean $[14,15]$.
} 
(i) $F^{(N-1)}(x) \leq G^{(N-1)}(x)$ for all $a \leq x \leq b$,

(ii) $F^{(i)}(b) \leq G^{(i)}(b)$ for $i=1, \ldots, N-2$.

We write $F$ NSD $G$ to denote that $F$ dominates $G$ via $N^{t h}$-order stochastic dominance. If the random variables $\widetilde{X}$ and $\widetilde{Y}$ have cumulative distribution functions $F$ and $G$ respectively, we also will take the liberty to say that $\widetilde{X} \operatorname{NSD} \widetilde{Y}$. For $N=1,2,3$, we will use the more common notations for first-, second-, and third-order stochastic dominance: FSD, SSD and TSD.

As a special case of stochastic dominance, Ekern [8] considers the following:

Definition 2 The distribution $G$ has more $N^{\text {th }}$-degree risk than the distribution $F$

if

(i) $F^{(N-1)}(x) \leq G^{(N-1)}(x)$ for all $a \leq x \leq b$,

(ii) $F^{(i)}(b)=G^{(i)}(b)$ for $i=1, \ldots, N-1$.

Note that $G$ has more $N^{t h}$-degree risk than $F$ is equivalent to saying that $F$ NSD $G$ and the first $N-1$ moments of $F$ and $G$ are identical. ${ }^{4}$

The following two theorems express the well-known links between stochastic dominance and expected utility, as well as Ekern's extension of this result to increases

\footnotetext{
${ }^{4}$ The second condition follows easily from part (ii) in Definition 2 by integrating both $F^{(i)}$ and $G^{(i)}$ by parts. The case where $N=3$ is labeled as an "increase in downside risk" and given special attention in a paper by Menezes et al. [21]. The case where $N=4$ is examined in part by Menezes and Wang [22].
} 
in $N^{t h}$ degree risk. ${ }^{5} \quad$ We let $u(w)$ denote the individual's utility function. For notational convenience, we use $u^{(n)}(w)$ to denote $\frac{d^{n} u(w)}{d w^{n}}$.

Theorem 1 The following are equivalent:

(i) F NSD G,

(ii) $\int_{a}^{b} u(t) d F \geq \int_{a}^{b} u(t) d G$, for all functions $u$ such that sgn $u^{(n)}(w)=(-1)^{n+1}$ for $n=1, \ldots, N$.

Theorem 2 The following are equivalent:

(i) G has more $N^{\text {th }}$ degree risk than $F$,

(ii) $\int_{a}^{b} u(t) d F \geq \int_{a}^{b} u(t) d G$, for all functions $u$ such that sgn $u^{(N)}(w)=(-1)^{N+1}$.

\section{Main Result}

In this section, we examine a particular lottery preference over random wealth variables that can be ordered via stochastic dominance. We then extend the result to increases in $i^{t h}$-degree risk.

Let $[A, B]$ denote a lottery that pays either $A$ or $B$, each with probability one-half. Consider the mutually independent random variables $\tilde{X}_{N}, \tilde{Y}_{N}, \tilde{X}_{M}$ and $\tilde{Y}_{M}$, and

\footnotetext{
${ }^{5}$ See Hadar and Russell [11] and Hanoch and Levy [12] who introduced this notion into the economics literature for SSD. See Jean [14] and Whitmore [27], as well as Ingersoll [13] for extensions to higher orders of stochastic dominance.
} 
assume that $\widetilde{X}_{i}$ dominates $\widetilde{Y}_{i}$ via $i^{t h}$-order stochastic dominance for $i=M, N$. We wish to compare the 50-50 lotteries $\left[\widetilde{X}_{N}+\widetilde{Y}_{M}, \widetilde{Y}_{N}+\widetilde{X}_{M}\right]$ and $\left[\widetilde{X}_{N}+\widetilde{X}_{M}, \widetilde{Y}_{N}+\widetilde{Y}_{M}\right]$.

Theorem 3 Suppose that $\widetilde{X}_{i}$ dominates $\widetilde{Y}_{i}$ via $i^{\text {th }}$-order stochastic dominance for $i=$ M,N. The lottery $\left[\widetilde{X}_{N}+\tilde{Y}_{M}, \tilde{Y}_{N}+\widetilde{X}_{M}\right]$ dominates the lottery $\left[\tilde{X}_{N}+\widetilde{X}_{M}, \widetilde{Y}_{N}+\widetilde{Y}_{M}\right]$ via $(N+M)^{\text {th }}$-order stochastic dominance.

Proof. Let $T$ be a positive integer and define $U_{T} \equiv\left\{u \mid \operatorname{sgn} u^{(n)}(w)=(-1)^{n+1}\right.$ for $n=1, \ldots, T\}$. For an arbitrary function $u \in U_{N+M}$ define $v(w) \equiv E u\left(\widetilde{Y}_{M}+\right.$ $w)-E u\left(\widetilde{X}_{M}+w\right)$, where $E$ denotes the expectation operator. We first show that $v \in U_{N}$. To see this, consider any integer $k, 1 \leq k \leq N$. Observe that $(-1)^{k} u^{(k)} \in$ $U_{N+M-k} \subset U_{M}$. Now sgn $v^{(k)}(w)=\operatorname{sgn}\left[E u^{(k)}\left(\widetilde{Y}_{M}+w\right)-E u^{(k)}\left(\widetilde{X}_{M}+w\right)\right]=(-1)^{k+1}$. The second equality above follows since $(-1)^{k} u^{(k)} \in U_{M}$ and $\widetilde{X}_{M}$ MSD $\widetilde{Y}_{M}$. Thus, $v \in U_{N}$

The condition that $\widetilde{X}_{N}$ dominates $\widetilde{Y}_{N}$ via $N^{t h}$-order stochastic dominance, together with $v \in U_{N}$, implies that $E v\left(\widetilde{X}_{N}\right) \geq E v\left(\widetilde{Y}_{N}\right)$, which by the definition of $v$ is equivalent to

$$
E u\left(\tilde{X}_{N}+\widetilde{Y}_{M}\right)-E u\left(\tilde{X}_{N}+\tilde{X}_{M}\right) \geq E u\left(\widetilde{Y}_{N}+\widetilde{Y}_{M}\right)-E u\left(\widetilde{Y}_{N}+\widetilde{X}_{M}\right)
$$


Rearranging terms above, this inequality is equivalent to

$$
\frac{1}{2}\left\{E u\left(\widetilde{X}_{N}+\widetilde{Y}_{M}\right)+E u\left(\widetilde{Y}_{N}+\widetilde{X}_{M}\right)\right\} \geq \frac{1}{2}\left\{E u\left(\widetilde{X}_{N}+\widetilde{X}_{M}\right)+E u\left(\widetilde{Y}_{N}+\widetilde{Y}_{M}\right)\right\}
$$

which is precisely the lottery preference claimed in the theorem.

The lottery preference expressed in Theorem 3 is analogous to the notion of "disaggregating the harms" discussed by Eeckhoudt and Schlesinger [5], if we interpret the "harms" as sequentially replacing each of the $\widetilde{X}$ random variables with a $\widetilde{Y}$ random variable in the sum $\widetilde{X}_{N}+\widetilde{X}_{M}$. Or, said differently, it expresses a preference for lotteries that combine "relatively good" assets with "relatively bad" ones, where relatively good and bad are defined via stochastic dominance.

The preferences described here lead to a partial ordering of the four alternative sums of random variables, based upon stochastic dominance criteria:

$$
\widetilde{X}_{N}+\widetilde{X}_{M} \succ \widetilde{X}_{i}+\widetilde{Y}_{j} \succ \widetilde{Y}_{N}+\widetilde{Y}_{M} \text { for }(i, j) \in\{(M, N),(N, M)\} .
$$

Note that the sums $\widetilde{X}_{M}+\widetilde{Y}_{N}$ and $\widetilde{X}_{N}+\widetilde{Y}_{M}$ cannot be ordered via stochastic dominance. In the spirit of Menezes and Wang [22] we can refer to these two sums as the "inner risks" and the sums $\widetilde{X}_{N}+\widetilde{X}_{M}$ and $\widetilde{Y}_{N}+\widetilde{Y}_{M}$ as the "outer risks." Theorem 3 thus expresses a preference for a 50-50 lottery over the two inner risks as opposed to 
a 50-50 lottery over the two outer risks. ${ }^{6}$

The following Corollary extends our main result to Ekern's ordering by $N^{t h}$ degree risk. The proof follows easily from the proof of Theorem 3.

Corollary Suppose that $\tilde{Y}_{i}$ has more $i^{\text {th }}$-degree risk than $\tilde{X}_{i}$ for $i=M, N$. Then the lottery $\left[\widetilde{X}_{N}+\widetilde{X}_{M}, \widetilde{Y}_{N}+\widetilde{Y}_{M}\right]$ has more $(N+M)^{t h}$-degree risk than the lottery $\left[\tilde{X}_{N}+\tilde{Y}_{M}, \tilde{Y}_{N}+\tilde{X}_{M}\right]$

Of course, from its definition, stochastic dominance of order $i$ implies stochastic dominance of order $j, \forall j>i$. Still, one might wonder whether $(M+N)^{t h}$-order stochastic dominance is the best one can do in Theorem $3 .^{7}$ In particular, suppose in Theorem 3 that $\widetilde{X}_{i}$ does not dominate $\widetilde{Y}_{i}$ via $(i-1)^{t h}$-order stochastic dominance for $i \geq 2$. It is easy to derive examples for which the lottery $\left[\widetilde{X}_{N}+\widetilde{Y}_{M}, \widetilde{Y}_{N}+\widetilde{X}_{M}\right]$ dominates the lottery $\left[\widetilde{X}_{N}+\widetilde{X}_{M}, \widetilde{Y}_{N}+\widetilde{Y}_{M}\right]$ via $(N+M)^{t h}$-order stochastic dominance, but not for order $N+M-1$. Indeed, one can use any set of random variables satisfying the conditions of the Corollary. If $\widetilde{Y}_{i}$ has more $i^{\text {th }}$-degree risk than $\widetilde{X}_{i}$ for $i=M, N$, then $\widetilde{X}_{i}$ dominates $\widetilde{Y}_{i}$ via $i^{\text {th }}$-order stochastic dominance, but not of any lower order. Thus, the lottery $\left[\widetilde{X}_{N}+\widetilde{Y}_{M}, \widetilde{Y}_{N}+\widetilde{X}_{M}\right]$ cannot stochastically dominate the lottery $\left[\widetilde{X}_{N}+\widetilde{X}_{M}, \widetilde{Y}_{N}+\widetilde{Y}_{M}\right]$ for order $N+M-1$.

\footnotetext{
${ }^{6} \mathrm{~A}$ similar analogy is made by Eeckhoudt et al. [6], who describe a lattice structure on the ranking of the lottery components and subsequently define a preference functional over the lattice as being submodular.

${ }^{7}$ We thank a referee for being the "one" who first raised this issue with us.
} 
On the other hand, we can find examples of random variables that satisfy the conditions in Theorem 3, but for which the lotteries exhibit stochastic dominance of an order less than $M+N$. As one example, let $\widetilde{X}_{1} \equiv 2, \widetilde{Y}_{1} \equiv 0, \widetilde{X}_{2} \equiv[1.9(0.6), 10(0.4)]$ and $\widetilde{Y}_{2} \equiv[0,2]$, where the parentheses for $\tilde{X}_{2}$ are probabilities. Then it is straightforward to show that $\widetilde{X}_{1} \succeq_{1} \widetilde{Y}_{1}$ and $\widetilde{X}_{2} \succeq_{2} \widetilde{Y}_{2}$, with no first-order dominance for $\widetilde{X}_{2}$ over $\widetilde{Y}_{2} ;$ and yet $\left[\tilde{X}_{1}+\widetilde{Y}_{2}, \widetilde{Y}_{1}+\widetilde{X}_{2}\right] \succeq_{2}\left[\widetilde{X}_{1}+\widetilde{X}_{2}, \widetilde{Y}_{1}+\tilde{Y}_{2}\right] .^{8}$

Hence, the lotteries in Theorem 3 are guaranteed to satisfy $(M+N)^{t h}$-order stochastic dominance, but might or might not satisfy dominance of a lower order. Of course, as our first example above explains, by the Corollary we cannot have an increase in risk less than degree $M+N$.

\section{Applications}

In this section we illustrate the applicability of our results. In particular, we demonstrate how Theorem 3 and its Corollary can be used to gain additional insight into a few extant concepts such as downside risk aversion and precautionary demand for saving. We also show how our framework extends the notions of precautionary

\footnotetext{
${ }^{8}$ Recall that second-order stochastic dominance can be characterized by saying that the distribution of $\widetilde{Y}_{2}$ can be obtained from that of $\widetilde{X}_{2}$ by sequences of mean-preserving spreads and of shifts in probability mass to the left. In our example, the shifts to left are significant, whereas the mean-preserving spread is much less so. This leads to a lottery preference of order 2 , not just one of order 3.
} 
effects, tempering effects and risk apportionment.

\subsection{Downside Risk}

We first use an illustration that is the result of an experiment by Mao [20], and was used by Menezes et al. [21] to motivate the concept of aversion to downside risk (i.e. prudence). Consider the following two lotteries. Lottery A pays 1000 with a probability of $\frac{3}{4}$ and pays 3000 with a probability of $\frac{1}{4}$. Lottery B pays zero with a probability of $\frac{1}{4}$ and pays 2000 with a probability of $\frac{3}{4}$. Note that both lotteries have the same first two moments. Individuals who prefer lottery A to lottery B exhibit "downside risk aversion." 9

This lottery preference follows from our Corollary by defining

$$
\begin{aligned}
& \widetilde{X}_{1} \equiv 2000 \\
& \widetilde{Y}_{1} \equiv 1000 \\
& \widetilde{X}_{2} \equiv 0 \\
& \widetilde{Y}_{2} \equiv[-1000,+1000], \text { a } 50-50 \text { lottery. }
\end{aligned}
$$

\footnotetext{
${ }^{9} \mathrm{~A}$ recent experimental paper by Baltussen et al. [1] also supports this approach. Although they interpret their experiments for Prospect Theory, they use mean preserving spreads for "gains" and "losses," which we can reinterpret as "low wealth" and "high wealth" in our setting. We can interpret their results as showing a preference for attaching a mean-preserving spread to the higher wealth level, which is the equivalent of aversion to downside risk in our setting.
} 
Clearly $\widetilde{Y}_{1}$ is a first-order increase in risk over $\widetilde{X}_{1}$ and $\widetilde{Y}_{2}$ is a second-order increase in risk over $\widetilde{X}_{2}$. It is easily seen that $\mathrm{A}$ is the $50-50$ lottery $\left[\widetilde{X}_{1}+\widetilde{Y}_{2}, \widetilde{Y}_{1}+\widetilde{X}_{2}\right]$ and B is the 50-50 lottery $\left[\widetilde{X}_{1}+\widetilde{X}_{2}, \widetilde{Y}_{1}+\widetilde{Y}_{2}\right]$. Thus, from our Corollary, lottery B displays more third-order risk, i.e. displays more downside risk, so that anyone who is prudent (with $u^{\prime \prime \prime}>0$ in an expected utility framework) would prefer lottery A.

\subsection{Precautionary effects}

Consider a simple two-period model of consumption and saving. An individual with a time-separable preferences has a random labor income of $\widetilde{X}$ at date $t=0$ and income $\widetilde{Y}$ at date $t=1$. The individual decides to save some of her income at date $t=0$ and to consume the rest. She must decide on how much to save before learning the realized value of $\widetilde{X}$. Thus, her consumption at date $t=0$ is $\widetilde{X}-s$, where $s$ is the amount saved. If $s<0$, the consumer is borrowing money (i.e. negative savings) and consuming more than the realized value of $\widetilde{X}$ at date $t=0$. We assume that the interest rate for borrowing or lending is zero and that there is no time-discounting for valuing consumption at date $t=1$. At this date the individual consumes her income plus any savings, $\tilde{Y}+s$. Let $s^{*}$ denote the individual's optimal choice for savings.

Suppose that $\widetilde{X}$ dominates $\tilde{Y}$ via $N^{t h}$-order stochastic dominance. For any 
nonnegative scalar $\varphi \geq 0$, since $\varphi$ dominates $-\varphi$ by FSD, it follows from Theorem 3 that the 50-50 lottery $[(\widetilde{X}-\varphi),(\tilde{Y}+\varphi)]$ dominates $[(\widetilde{X}+\varphi),(\widetilde{Y}-\varphi)]$ by $(N+1)^{t h}$ order stochastic dominance . Reinterpreting the "50-50 lottery" $[A, B]$ as sequential consumption of $A$ at $t=0$ and $B$ at $t=1$, Theorem 3 implies that saving an arbitrary amount $\varphi \geq 0$ always dominates saving the amount $-\varphi$, whenever preferences satisfy $(N+1)^{t h}$-order stochastic dominance preference. It follows that we must have $s^{*} \geq 0$ for this individual.

For example, suppose that $\widetilde{X}$ is a constant equal to $E \widetilde{Y}$ and that preferences are given by expected utility. Then this result coincides with the classical case examined by Leland [19], Sandmo [26] and Kimball [16], for the case where preferences display prudence, $u^{\prime \prime \prime} \geq 0$. Even without an expected-utility preference functional, this precautionary saving demand $\left(s^{*} \geq 0\right)$ would extend to any preferences that dislike an increase in third-degree risk, as defined by Ekern [8]. Moreover, we can now easily extend this basic result in several directions:

(1) Suppose that one's labor income is risky in both periods, but it is riskier in the sense of a second-degree increase in risk at date $t=1$. Anyone with preferences exhibiting an aversion to downside risk (i.e. prudence) would prefer to save money rather than to borrow money.

(2) As opposed to (1), suppose that income in the second period is stochastically 
lower in the sense of FSD. In that case, aversion to downside risk is no longer required to generate a demand for precautionary saving. We only need someone to be averse to risk increases of degree two, i.e. aversion to mean-preserving spreads.

(3) We can extend (1) to the case where second period wealth is riskier via SSD by using Theorem 3: A precautionary saving demand then requires both aversion to downside risk and aversion to mean preserving spreads.

(4) Finally, we get the general case stated above, where $\widetilde{X}$ dominates $\widetilde{Y}$ via $N^{\text {th }}$-order stochastic dominance: A precautionary demand is generated whenever preferences satisfy $(N+1)^{t h}$-degree stochastic dominance preference.

\subsection{A Non-Precautionary Example}

We consider here an example applying Theorem 3 with $N=1$ and $M=2$, but that is not an example of a precautionary effect. Consider a risk-neutral corporation with taxable profit $\widetilde{X}$ in country $A$ and taxable profit $\widetilde{Y}$ in country $B$. We assume that the tax schedule is identical in both countries and that $\widetilde{X}$ SSD $\widetilde{Y}$. The tax owed on realized profit $\pi$ is denoted by $t(\pi)$. The tax schedule is assumed to be increasing with a marginal tax rate that is also increasing, but at a decreasing rate. ${ }^{10}$ After tax profits can thus be written as $u(\pi)=\pi-t(\pi)$. If $t(\cdot)$ is differentiable,

\footnotetext{
${ }^{10}$ This assumption is realistic since the marginal rate is often bounded by some maximum, such as fifty percent of additional profit, and certainly is strictly bounded by 100 percent.
} 
our assumptions about $t$ imply that $u^{\prime \prime}(\pi)<0$ and $u^{\prime \prime \prime}(\pi)>0$. Moreover, since we should also have $t^{\prime}(\pi)<1$ for any profit level $\pi$, it follows that $u^{\prime}(\pi)>0$ as well.

Suppose now that the corporation has a new project with a pre-tax distribution

of profit $\widetilde{Z}$, where $\widetilde{Z}>0$ a.s. The corporation must decide whether to locate the project in country $A$ or in country $B$. The after-tax total profit of the corporation is given by $u\left(\pi_{A}\right)+u\left(\pi_{B}\right)$, where $\pi_{i}$ denotes the realized pre-tax profit in country $i$, for $i=A, B$. Since $\widetilde{Z}$ dominates zero by FSD, it follows from Theorem 3 that $E[u(\widetilde{X})+u(\widetilde{Y}+\widetilde{Z})]>E[u(\widetilde{X}+\widetilde{Z})+u(\widetilde{Y})]$, since the valuation function $u$ (i.e. aftertax profits) satisfies third-order stochastic dominance preference. Thus, the firm should locate the new project in country $B$ in order to maximize its global after-tax profit.

\subsection{Tempering Effects of Risk}

Eeckhoudt and Schlesinger [5] define temperance using zero-mean risks, which hence display more second-degree risk than zero. By our Corollary, we know that temperance is equivalent to this lottery preference for any $\left\{\widetilde{X}_{a}, \widetilde{X}_{b}, \widetilde{Y}_{b}, \widetilde{Y}_{a}\right\}$ with $\widetilde{Y}_{i}$ having more second-degree risk than $\tilde{X}_{i}, i=a, b$, not just the particular case with $\widetilde{X}_{a}=\widetilde{X}_{b}=0$. Moreover, if we restrict individuals to those being risk averse (defined as an aversion to mean-preserving spreads) and prudent, then they will be temperate 
if and only if they exhibit the lottery preference in Theorem 3 with $N=M=2$.

Kimball [17] defines a key behavior consequence of temperance; namely, that an unavoidable risk will "lead an agent to reduce exposure to another [independent] risk." In our model, we obtain a variant of Kimball's tempering effect: an unavoidably higher level of risk in one state will lead one to reduce exposure to a second risk in that state. ${ }^{11}$ Here, higher or lower "risk" is characterized via SSD.

We can easily extend the notion of tempering effects to higher orders of risk. For example, Lajeri [18] studies the effects of background risks on precautionary savings and in doing so, examines the condition of decreasing absolute temperance. A necessary condition for this property within her expected-utility framework is $u^{(5)}>0$, which she labels as "edginess." By choosing $M=2$ and $N=3$, we can interpret edginess as implying that a decrease in one risk (via SSD) helps to temper the effects of an increase in downside risk of another additive risk.

Interestingly, we can obtain a second equivalence for temperance that has nothing whatsoever to do with tempering effects, by letting $N=3$ and $M=1 . \quad$ Let $\widetilde{Y}_{a}$ be an increase in downside risk over $\widetilde{X}_{a}$ (as in Section 4.1), and let $\widetilde{X}_{b}$ FSD $\widetilde{Y}_{b}$. The (stochastically) higher wealth in $\widetilde{X}_{b}$ helps to mitigate the effects of the increased downside risk in $\widetilde{Y}_{a}$. Thus, we prefer to pair $\widetilde{X}_{b}$ together with $\widetilde{Y}_{a}$ in our

\footnotetext{
${ }^{11}$ Our decision concerns where to allocate a second unavoidable risk. The optimal level of an endogenous second risk is examined by Gollier and Pratt [10].
} 
lottery preference. In the special case where $\widetilde{X}_{b}$ and $\widetilde{Y}_{b}$ are both constants, we get a precautionary effect as previously described. But note how this equivalence for "temperance" does not describe any type of tempering effect. Instead, it implies that the property of temperance yields a precautionary effect in protecting against increases in downside risk of future labor income. Similarly, by choosing $M=1$ and $N=4$, we can use our Corollary to interpret edginess as implying a precautionary effect against increases in fourth-degree risk for future labor income.

\subsection{Risk Apportionment}

We can characterize risk apportionment, as defined by Eeckhoudt and Schlesinger [5], by setting $\widetilde{X}_{i}=0$, so that we have $0 \succeq_{i} \widetilde{Y}_{i}$. If this partial ordering is determined via $i^{t h}$-order increases in risk, their characterization of risk apportionment results as a special case of our model, with $M+N$ equal to the degree of risk apportionment. For example, for $M+N=6$, define $\widetilde{X}_{2}=0, \widetilde{Y}_{2}=\widetilde{\varepsilon}_{3}, \widetilde{X}_{4}=\left[\widetilde{\varepsilon}_{1}, \widetilde{\varepsilon}_{2}\right], \widetilde{Y}_{4}=\left[0, \widetilde{\varepsilon}_{1}+\widetilde{\varepsilon}_{2}\right]$, where the $\widetilde{\varepsilon}_{i}$ are all mutually independent zero-mean risks. It follows that $\widetilde{X}_{2} \succeq_{2} \widetilde{Y}_{2}$ and $\widetilde{X}_{4} \succeq_{4} \tilde{Y}_{4}$. The Corollary then gives us the precise decomposition for risk apportionment of order 6, as described in Eeckhoudt and Schlesinger [5, Figure 1]. Our approach extends their risk apportionment characterizations, by replacing $i^{\text {th }}$ degree risk orderings with orderings by $i^{\text {th }}$-order stochastic dominance. 
Higher-order risk effects, such as prudence and temperance, are being examined in non-expected utility models, which hitherto have used various ways to even define such concepts, e.g. Chateauneuf et al. [3] and Eichner [7]. The lottery preferences we use to characterize prudence, temperance, and higher orders of risk apportionment also can be applied within such non-expected utility models.

It is worth noting that our main results are not utility based. Stochastic dominance and increases in $i^{t h}$-order risks are purely statistical properties. Indeed, the $u$ functions used in our proof of Theorem 3 need not represent anyone's utility; they are used only as a mathematical device in the proof.

\section{Concluding Remarks}

Hedging has long been a capstone of risk-management strategy. Faced with an initially risky wealth prospect, one can add a position in another asset whose payoff is negatively correlated to the original risky wealth. Such an asset will usually have a positive net payoff in states of the world in which the random wealth would otherwise have been low. If we assume risk aversion, then marginal utility in low-wealth states is higher and therefore such a hedge is valuable to a risk averter. The cost of such hedging is that the net payoff is usually negative in states of the world in which the random wealth would otherwise have been high. In a certain sense, hedging pairs 
up relatively good outcomes on one asset with relatively bad outcomes on another asset, and vice versa.

By contrast, risk apportionment pairs relatively good assets with relatively bad ones. It assumes that the payoffs on the assets are independent, which is antithetical to the premise of hedging. Given the partial ordering in (3), we prefer a 50-50 gamble between the two "inner risks" as opposed to the two outer ones. Here relatively "good" and "bad" are determined via differences in $i^{t h}$-degree risk.

If we expand relatively "good" and "bad" to be defined by $i^{\text {th }}$-order stochastic dominance, then, under expected utility, this ranking coincides with a utility function (or some other valuation function) whose derivatives alternate in sign. If these rankings hold for all orders of stochastic dominance, then they would coincide with preferences that are completely monotone, as described by Brockett and Golden [2] and Pratt and Zeckhauser [24].

We provided several interpretations and applications of Theorem 3 and its Corollary. Our results also can be used to add intuition to many other extant concepts in the literature, such as skewness preference (see Chiu [4]) and transfer principles in income redistribution (see Fishburn and Willig [9] and Moyes [23]). Moreover, our results can be useful in situations where preferences over the lotteries are reversed. For example, a decision maker might prefer mean-preserving increases in risk over 
the domain of losses, or might prefer increases in downside risk over the domain of gains. ${ }^{12}$ The equivalences in our paper easily allow for such adaptation.

The lottery preference described in this paper extends the concept of "risk apportionment," as introduced by Eeckhoudt and Schlesinger [5]. One strength of their result is the simplicity of their characterization of lower levels of risk apportionment via a preference over simple 50-50 lotteries. However, their characterization is less simple for higher orders, since it requires that they construct larger and larger nestings of simple lotteries.

A strength of this paper is that we can characterize any degree of risk apportionment by a preference between two simple 50-50 lotteries that differ in their levels of $i^{t h}$-degree risk. In some instances, decisions are indeed about how to apportion "lotteries" across two states (or two time periods, or two firms, or two groups of people). Our model shows how such decisions often can be made independent of a particular utility function or even a particular preference functional, as long as we believe that valuations exhibit aversion to increases in $i^{\text {th }}$-degree risk. Moreover, our extension of risk apportionment to stochastic dominance rankings should prove quite useful in future research, since stochastic dominance rankings are more common in

\footnotetext{
${ }^{12}$ For example, Wong [28] essentially defines the first three orders of stochastic dominance over the de-cumulative distribution function and refers to these respectively as "descending stochastic dominance" of each order.
} 
the extant literature.

\section{References}

[1] G. Baltussen, T. Post, P. van Vliet, Violations of cumulative prospect theory in mixed gambles with moderate probabilities, Management Sci. 52 (2006), 12881290.

[2] P. Brockett, L. Golden, A class of utility functions containing all the common utility functions, Management Sci. 33 (1987), 955-964.

[3] A. Chateauneuf, G. Lakhnati, E. Langlais, On the precautionary motive for savings and prudence, in an EU and NEU framework, Working Paper, University of Paris 1 (2005), available at www.ssrn.com/abstract=693721.

[4] H. Chiu, Skewness preference, risk aversion, and the precedence relations on stochastic changes, Management Sci. 51 (2005), 1816-1828.

[5] L. Eeckhoudt, H. Schlesinger, Putting risk in its proper place, Amer. Econ. Rev. 96 (2006), 280-289 
[6] L. Eeckhoudt, B. Rey, H. Schlesinger, A good sign for multivariate risk taking." Management Sci. 53 (2007), 117-124.

[7] T. Eichner, Mean-variance vulnerability, Management Sci. 54 (2008), 586-593.

[8] S. Ekern, Increasing $N^{\text {th }}$ degree risk." Econ. Letters 6 (1980), 329-33.

[9] P.C. Fishburn, R.D. Willig, Transfer principles in income redistribution, J. Public Econ. 25 (1984), 323-328

[10] C. Gollier, J.W. Pratt, Risk vulnerability and the tempering effect of background risk, Econometrica 64 (1996), 1109-1124.

[11] J. Hadar, W.R. Russell, Rules for ordering uncertain prospects." Amer. Econ. Rev. 59 (1969), 25-34.

[12] G. Hanoch, H. Levy, Efficiency analysis of choices involving risk." Rev. Econ. Stud. 36 (1969), 335-346.

[13] J.E. Ingersoll, Theory of Financial Decision Making, Rowman \& Littlefield, Lanham, MD, 1987.

[14] W.H. Jean, The geometric mean and stochastic dominance, J. Finance 35 (1980), 151-158. 
[15] W.H. Jean, The harmonic mean and other necessary conditions for stochastic dominance, J. Finance 39 (1984), 527-534.

[16] M.S. Kimball, Precautionary savings in the small and in the large, Econometrica 58 (1990), 53-73.

[17] M.S. Kimball, Precautionary motives for holding assets, in: P. Newman, M. Milgate, J. Falwell (Eds.), The New Palgrave Dictionary of Money and Finance, Stockton Press, New York, 1992, pp. 158-161.

[18] F. Lajeri-Chaherli, Proper prudence, standard prudence and precautionary vulnerability, Econ. Letters 82 (2004), 29-34.

[19] H.E. Leland, Saving and uncertainty: the precautionary demand for saving, Quart. J. Econ. 82 (1968), 465-73.

[20] J.C. Mao, Survey of capital budgeting: theory and practice, J. Finance 25 (1970), 349-360.

[21] C.F. Menezes, C. Geiss, J. Tressler, Increasing downside risk, Amer. Econ. Rev. 70 (1980), 921-32.

[22] C.F. Menezes, H. Wang, Increasing outer risk, J. Math. Econ. 41 (2005), 875-86. 
[23] P. Moyes, Stochastic dominance and the Lorenz curve, in: J. Silber (Ed.), Handbook of Income Inequality Measurement, Kluwer Academic Publishers, Boston, 1999, pp. 199-222.

[24] J.W. Pratt, R. Zeckhauser, Proper risk aversion, Econometrica 55 (1987), 143154.

[25] M. Rothschild, J.E. Stiglitz, Increasing risk: I. a definition, J. Econ. Theory 2 (1970), 225-243.

[26] A. Sandmo, The effect of uncertainty on saving decisions, Rev. Econ. Stud. 37 (1970), 353-60.

[27] G.A. Whitmore, Stochastic dominance for the class of completely monotone utility functions, in: T.B. Fomby, T.K. Seo (Eds.), Studies in the Economics of Uncertainty - In Honor of Josef Hadar, Springer Verlag, New York, 1989, pp. $77-88$.

[28] W.-K. Wong, Stochastic dominance and the mean-variance measure of profit and loss for business planning and investment, Europe. J. Operational Management 182 (2007), 829-843.

[29] I. Zilcha, H.S. Chew, Invariance of the efficient sets when the expected utility hypothesis is relaxed, J. Econ. Behav.Organ. 13 (1990), 125-131. 


\section{CESifo Working Paper Series}

for full list see www.cesifo-group.org/wp

(address: Poschingerstr. 5, 81679 Munich, Germany, office@cesifo.de)

2405 Leonidas Enrique de la Rosa, Overconfidence in a Career-Concerns Setting, September 2008

2406 Marcus Drometer and Johannes Rincke, The Design of Political Institutions: Electoral Competition and the Choice of Ballot Access Restrictions in the United States, September 2008

2407 Markku Lanne and Helmut Lütkepohl, Stock Prices and Economic Fluctuations: A Markov Switching Structural Vector Autoregressive Analysis, September 2008

2408 Thomas L. Brewer, International Energy Technology Transfers for Climate Change Mitigations, September 2008

2409 Alexander Kemnitz, Native Welfare Losses from High Skilled Immigration, September 2008

2410 Xavier Vives, Strategic Supply Function Competition with Private Information, September 2008

2411 Fabio Padovano and Roberto Ricciuti, The Political Competition-Economic Performance Puzzle: Evidence from the OECD Countries and the Italian Regions, September 2008

2412 Joan Costa-Font and Mireia Jofre-Bonet, Body Image and Food Disorders: Evidence from a Sample of European Women, September 2008

2413 Thorsten Upmann, Labour Unions - To Unite or to Separate?, October 2008

2414 Sascha O. Becker and Ludger Woessmann, Luther and the Girls: Religious Denomination and the Female Education Gap in $19^{\text {th }}$ Century Prussia, October 2008

2415 Florian Englmaier and Stephen Leider, Contractual and Organizational Structure with Reciprocal Agents, October 2008

2416 Vittorio Daniele and Ugo Marani, Organized Crime and Foreign Direct Investment: The Italian Case, October 2008

2417 Valentina Bosetti, Carlo Carraro, Alessandra Sgobbi and Massimo Tavoni, Modelling Economic Impacts of Alternative International Climate Policy Architectures. A Quantitative and Comparative Assessment of Architectures for Agreement, October 2008

2418 Paul De Grauwe, Animal Spirits and Monetary Policy, October 2008 
2419 Guglielmo Maria Caporale, Christophe Rault, Robert Sova and Anamaria Sova, On the Bilateral Trade Effects of Free Trade Agreements between the EU-15 and the CEEC-4 Countries, October 2008

2420 Yin-Wong Cheung and Daniel Friedman, Speculative Attacks: A Laboratory Study in Continuous Time, October 2008

2421 Kamila Fialová and Ondřej Schneider, Labour Market Institutions and their Effect on Labour Market Performance in the New EU Member Countries, October 2008

2422 Alexander Ludwig and Michael Reiter, Sharing Demographic Risk - Who is Afraid of the Baby Bust?, October 2008

2423 Doina Maria Radulescu and Michael Stimmelmayr, The Welfare Loss from Differential Taxation of Sectors in Germany, October 2008

2424 Nikolaus Wolf, Was Germany ever United? Evidence from Intra- and International Trade 1885 - 1933, October 2008

2425 Bruno S. Frey, David A. Savage and Benno Torgler, Noblesse Oblige? Determinants of Survival in a Life and Death Situation, October 2008

2426 Giovanni Facchini, Peri Silva and Gerald Willmann, The Customs Union Issue: Why do we Observe so few of them?, October 2008

2427 Wido Geis, Silke Uebelmesser and Martin Werding, Why go to France or Germany, if you could as well go to the UK or the US? Selective Features of Immigration to four major OECD Countries, October 2008

2428 Geeta Kingdon and Francis Teal, Teacher Unions, Teacher Pay and Student Performance in India: A Pupil Fixed Effects Approach, October 2008

2429 Andreas Haufler and Marco Runkel, Firms' Financial Choices and Thin Capitalization Rules under Corporate Tax Competition, October 2008

2430 Matz Dahlberg, Heléne Lundqvist and Eva Mörk, Intergovernmental Grants and Bureaucratic Power, October 2008

2431 Alfons J. Weichenrieder and Tina Klautke, Taxes and the Efficiency Costs of Capital Distortions, October 2008

2432 Andreas Knabe and Ronnie Schöb, Minimum Wage Incidence: The Case for Germany, October 2008

2433 Kurt R. Brekke and Odd Rune Straume, Pharmaceutical Patents: Incentives for R\&D or Marketing?, October 2008

2434 Scott Alan Carson, Geography, Insolation, and Institutional Change in $19^{\text {th }}$ Century African-American and White Stature in Southern States, October 2008 
2435 Emilia Del Bono and Daniela Vuri, Job Mobility and the Gender Wage Gap in Italy, October 2008

2436 Marco Angrisani, Antonio Guarino, Steffen Huck and Nathan Larson, No-Trade in the Laboratory, October 2008

2437 Josse Delfgaauw and Robert Dur, Managerial Talent, Motivation, and Self-Selection into Public Management, October 2008

2438 Christian Bauer and Wolfgang Buchholz, How Changing Prudence and Risk Aversion Affect Optimal Saving, October 2008

2439 Erich Battistin, Clara Graziano and Bruno Parigi, Connections and Performance in Bankers' Turnover: Better Wed over the Mixen than over the Moor, October 2008

2440 Erkki Koskela and Panu Poutvaara, Flexible Outsourcing and the Impacts of Labour Taxation in European Welfare States, October 2008

2441 Marcelo Resende, Concentration and Market Size: Lower Bound Estimates for the Brazilian Industry, October 2008

2442 Giandomenico Piluso and Roberto Ricciuti, Fiscal Policy and the Banking System in Italy. Have Taxes, Public Spending and Banks been Procyclical in the Long-Run? October 2008

2443 Bruno S. Frey and Katja Rost, Do Rankings Reflect Research Quality?, October 2008

2444 Guglielmo Maria Caporale, Antoaneta Serguieva and Hao Wu, Financial Contagion: Evolutionary Optimisation of a Multinational Agent-Based Model, October 2008

2445 Valentina Bosetti, Carlo Carraro and Massimo Tavoni, Delayed Participation of Developing Countries to Climate Agreements: Should Action in the EU and US be Postponed?, October 2008

2446 Alexander Kovalenkov and Xavier Vives, Competitive Rational Expectations Equilibria without Apology, November 2008

2447 Thiess Buettner and Fédéric Holm-Hadulla, Cities in Fiscal Equalization, November 2008

2448 Harry H. Kelejian and Ingmar R. Prucha, Specification and Estimation of Spatial Autoregressive Models with Autoregressive and Heteroskedastic Disturbances, November 2008

2449 Jan Bouckaert, Hans Degryse and Thomas Provoost, Enhancing Market Power by Reducing Switching Costs, November 2008

2450 Frank Heinemann, Escaping from a Combination of Liquidity Trap and Credit Crunch, November 2008 
2451 Dan Anderberg, Optimal Policy and the Risk Properties of Human Capital Reconsidered, November 2008

2452 Christian Keuschnigg and Evelyn Ribi, Outsourcing, Unemployment and Welfare Policy, November 2008

2453 Bernd Theilen, Market Competition and Lower Tier Incentives, November 2008

2454 Ondřej Schneider, Voting in the European Union - Central Europe's Lost Voice, November 2008

2455 Oliver Lorz and Gerald Willmann, Enlargement versus Deepening: The Trade-off Facing Economic Unions, November 2008

2456 Alfons J. Weichenrieder and Helen Windischbauer, Thin-Capitalization Rules and Company Responses, Experience from German Legislation, November 2008

2457 Andreas Knabe and Steffen Rätzel, Scarring or Scaring? The Psychological Impact of Past Unemployment and Future Unemployment Risk, November 2008

2458 John Whalley and Sean Walsh, Bringing the Copenhagen Global Climate Change Negotiations to Conclusion, November 2008

2459 Daniel Mejía, The War on Illegal Drugs in Producer and Consumer Countries: A Simple Analytical Framework, November 2008

2460 Carola Frydman, Learning from the Past: Trends in Executive Compensation over the Twentieth Century, November 2008

2461 Wolfgang Ochel, The Political Economy of Two-tier Reforms of Employment Protection in Europe, November 2008

2462 Peter Egger and Doina Maria Radulescu, The Influence of Labor Taxes on the Migration of Skilled Workers, November 2008

2463 Oliver Falck, Stephan Heblich and Stefan Kipar, The Extension of Clusters: Differencein-Differences Evidence from the Bavarian State-Wide Cluster Policy, November 2008

2464 Lei Yang and Keith E. Maskus, Intellectual Property Rights, Technology Transfer and Exports in Developing Countries, November 2008

2465 Claudia M. Buch, The Great Risk Shift? Income Volatility in an International Perspective, November 2008

2466 Walter H. Fisher and Ben J. Heijdra, Growth and the Ageing Joneses, November 2008

2467 Louis Eeckhoudt, Harris Schlesinger and Ilia Tsetlin, Apportioning of Risks via Stochastic Dominance, November 2008 